\title{
Endogenous Nocardia asteroides endophthalmitis in a patient with systemic lupus erythematosus
}

\author{
Y Ishibashi, R Watanabe, S Hommura, A Koyama, T Ishikawa, Y Mikami
}

Institute of Clinical Medicine, University of Tsukuba, Tsukuba Department of Ophthalmology Y Ishibashi

R Watanabe

S Hommura

Department of Internal Medicine

A Koyama

T Ishikawa

Research Centre for Pathogenic Fungi and Microbial Toxicoses, Chiba University, Chiba, Japan

Y Mikami

Correspondence to:

Dr Y Ishibashi,

Drepartment of

Department of
Ophthalmology, Institute

of Clinical Medicine,

University of Tsukuba,

Tsukuba-shi, Ibaraki, 305 Japan.

Accepted for publication 2 February 1990

\begin{abstract}
We report a case of endogenous Nocardia endophthalmitis in a patient with systemic lupus erythematosus (SLE). He developed a parafoveal lesion in the right fundus while on systemic corticosteroid and antibiotic treatment. Initially we suspected a fungal origin and treated him with antifungal drugs. The intraocular disease progressed without improvement and advanced to the vitreous cavity. Nocardia asteroides was found in a specimen obtained at pars plana vitrectomy and was also cultured from the same specimen. The intraocular infection was controlled by antibacterial drugs, though the visual acuity of the right eye was reduced to only light perception owing to heavy vitreous opacity and secondary cataract. This case is the first report of endogenous Nocardia endophthalmitis in Japan and also the first case of this disease reported from outside the United States of America.
\end{abstract}

Nocardia asteroides is a Gram-positive, weakly acid-fast, filamentous, aerobic organism which is generally considered to be a bacterium despite certain morphological and staining properties in common with fungi. ${ }^{1}$ The clinical features of nocardial infection closely resemble those of fungal infections, though Nocardia has no sensitivity to antifungal agents. It is evident from some studies that nocardiosis is a disease of much greater frequency than was formerly recognised. ${ }^{23}$ Lung, skin and subcutaneous tissue, brain, and pleura are common sites of the infection. Haematogenous dissemination, usually from a primary pulmonary focus, has been estimated to occur in approximately onethird of the cases. Intraocular infection, a rare site, has been reported in 14 patients, ${ }^{4-14}$ typically leading to enucleation or death. Endogenous ocular dissemination has been found in patients with renal transplants, ${ }^{78}$ lymphocytic lymphoma, ${ }^{9} \quad$ hypogammaglobulinaemia. ${ }^{10}$ Hodgkin's disease, ${ }^{11}$ lupus erythematosus, ${ }^{12}$ diabetes mellitus, ${ }^{13}$ and systemic sclerosis. ${ }^{14} \mathrm{We}$ observed endogenous Nocardia endophthalmitis in a patient with systemic lupus erythematosus (SLE).

\section{Case report}

The subject was a 27-year-old man who had a history of admission to hospital with systemic eruption, fever, nasal bleeding, and photosensitivity. He was diagnosed as having systemic lupus erythematosus by a biopsy of the kidney when he was 14 years old. He was also admitted to hospital at 16 years old, 19 years old, and 24 years old with various symptoms considered to be unrelated to the systemic lupus erythematosus. The histopathological diagnosis by biopsy of the kidney was diffuse mesangial proliferation with adhesions, at his last admission to hospital. He took oral corticosteroid (prednisolone $10 \mathrm{mg} /$ day) as an outpatient but stopped suddenly without consulting his doctor.

The patient developed systemic oedema and ascites, symptoms of nephrotic syndrome, at the beginning of March 1987, and entered the University Hospital of Tsukuba on 15 May, 1987. His condition was controlled with $60 \mathrm{mg}$ of oral prednisolone. He had a fever of $39^{\circ} \mathrm{C}$ on 1 August. Multiple nodular shadows in the lungs were found on $x$-ray (Fig 1 ), and cavity formation was disclosed by roentogeno-tomography. The fever was reduced to $37^{\circ} \mathrm{C}$ by administration of antibiotics, but the patient complained of blurred vision in his right eye on 19 August. He
Figure 1: Chest $x$-ray showed multiple nodular shadows in the lung (arrows) when the patien had a fever of $39^{\circ} \mathrm{C}$. 


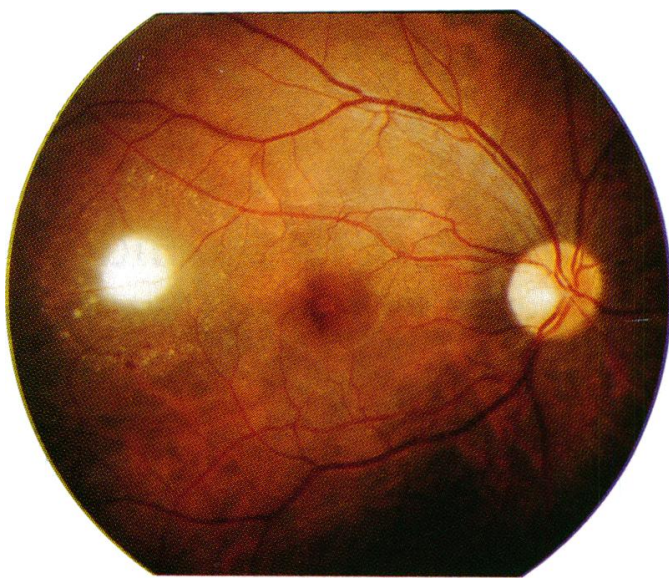

Figure 2: Right ocular fundus of the patient at initial examination. Temporal to the macula is an exudative lesion with thin retinal detachment.

was referred to the Department of Ophthalmology on 27 August 1987.

The visual acuity of his right eye was 20/25, and a slit-lamp examination disclosed a mildly inflamed conjunctiva. There was a moderate inflammatory reaction in the anterior chamber and vitreous body. No changes were recognised in the cornea or the lens. Ophthalmoscopic examination of the right eye disclosed a paramacular exudative lesion located temporally of the macula. The lesion was round, whitish yellow, $1 \mathrm{~mm}$ in diameter, slightly elevated towards the vitreous cavity, with a thin retinal detachment (Fig 2). In the left eye there were mild inflammatory cells in the anterior chamber and vitreous body, but no changes were found in the cornea, lens, or fundus.

We suspected initially fungal infection from his history and clinical features; moreover a Candida sp. was found in a culture of sputum. Itraconazole, $150 \mathrm{mg} /$ day by mouth, a new triazole antifungal agent, was started for the ocular infection. Despite this treatment the retinal lesion developed gradually (Fig 3). Intravenous miconazole $1200 \mathrm{mg} /$ day, was added to the therapy on 6 September, but the infection progressed without improvement. Pars plana vitrectomy with miconazole infusion $(100 \mathrm{mg} / \mathrm{l})$ was performed on 18 September, 1987. Grampositive, filamentous organisms (Fig 4) were found in the specimen obtained at vitrectomy,

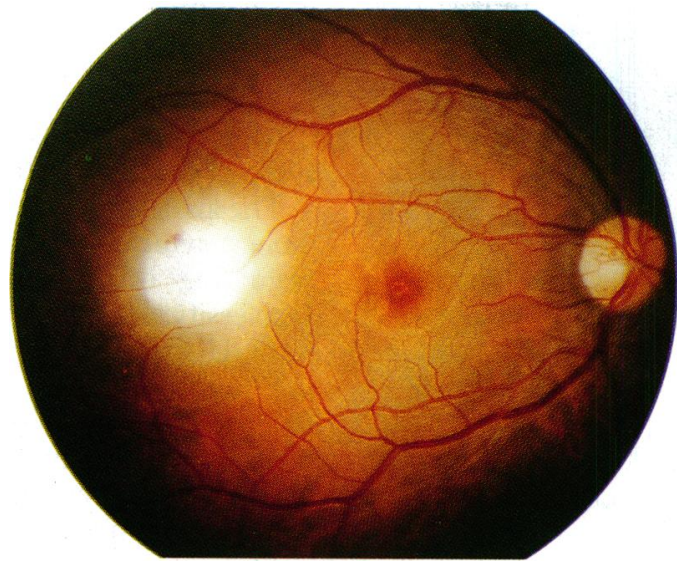

Figure 3: One week later the ocular lesion had gradually progressed in spite of taking oral itraconazole.

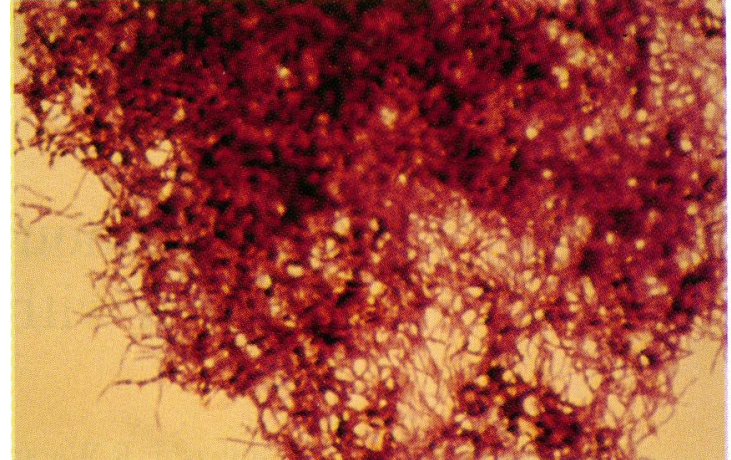

Figure 4: Gram-positive, filamentous organisms were found in the specimen obtained from a pars plana vitrectomy. (Gram stain, original magnification, $\times 100)$.

and many orange colonies grew on heart infusion agar. This organism was determined as Nocardia asteroides by morphological features on Sabouraud agar and brain heart infusion agar (Fig 5), by microscopic features on a slide culture, and by biochemical and physiological studies such as analysis of cell wall compositions, ability to hydrolyse adenine, caseine, hypoxanthine, tyrosine, urea, or xanthine, and utilisation of acid production from various carbon sources.

Immediately after the diagnosis of nocardiosis on 22 September, 1987 the treatment was changed to oral trimethoprim $(1600 \mathrm{mg})$ and sulfamethoxazole $(320 \mathrm{mg})$ per day, but the ocular infection did not improve. On 30 September, in line with the results of a sensitivity test (Table I), intravenous cefotaxime ( $2 \mathrm{~g} /$ day), oral minocycline (200 mg/day), and intramuscular amikacin $(100 \mathrm{mg} /$ day $)$ were started instead of trimethoprim and sulphamethoxazole. The ocular infection reacted gradually to this therapy. On 13 October, the doses of these drugs were reduced to $1 \mathrm{~g}$ of cefotaxime, $100 \mathrm{mg}$ of minocycline, and $50 \mathrm{mg}$ of amikacin. During this time intraocular and pulmonary infections were well controlled by the therapy.

After one month of treatment the infection had subsided, though the right ocular fundus was not observable, and visual acuity was reduced to only light perception because of secondary cataract and heavy vitreous opacity. There were no signs of chronic inflammation in his right eye, and B-scan ultrasonography

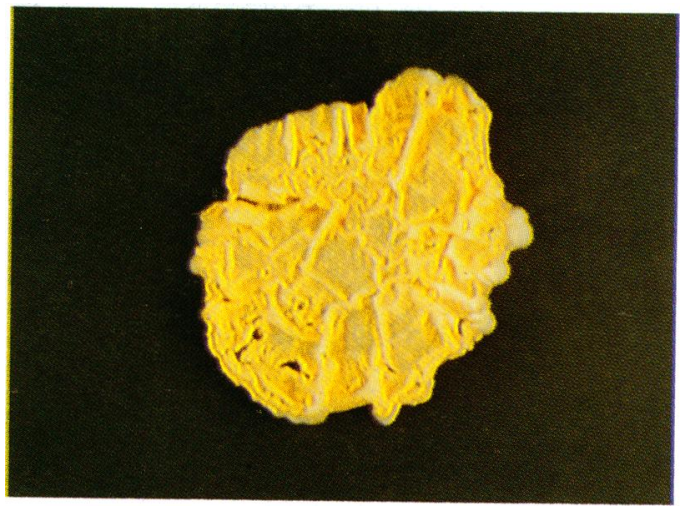

Figure 5: A macrocolony of Nocardia asteroides on brain-heart infusion agar (Difco) for three weeks at $27^{\circ} \mathrm{C}$. The size of colony was 20 to $35 \mathrm{~mm}$ in diameter. 
TABLE I In vitro susceptibility of this strain of Nocardia asteroides to various antimicrobial agents

\begin{tabular}{lc}
\hline Agent & MIC value $(\mathrm{mg} / \mathrm{l})^{\star}$ \\
\hline Ampicillin & $100 \cdot 00$ \\
Amikacin & 0.78 \\
Cefotaxime & $3 \cdot 12$ \\
Gentamicin & $50 \cdot 0$ \\
Doxycycline & $1 \cdot 5$ \\
Minocycline & $0 \cdot 39$ \\
TMP-SMX $\dagger$ & $25 \cdot 0$ \\
SMX & $100 \cdot 0$ \\
\hline
\end{tabular}

^ Minimum inhibitory concentration (MIC) was defined as the lowest concentration suppressing all growth during seven days of incubation at $27^{\circ} \mathrm{C}$. Sensitivity disc agar (Nissui, Japan) was used. †TMP=Trimethoprim. SMX = sulfamethoxazole, combination in fixed-weight ratio $(1: 5)$.

showed no retinal detachment at the end of therapy. Moreover, the left eye had no inflammation in the anterior chamber or the vitreous, and the visual acuity remained at 20/20. The pulmonary infection also reacted to the systemic treatment, and the patient was discharged on 18 November, 1987.

\section{Discussion}

Endogenous Nocardia endophthalmitis is disseminated from the primary site of infection, mainly from pulmonary lesions, and has been reported in only 14 patients (Table II). All were from the United States. In 1961 Murray and associates ${ }^{3}$ stated that no documented cases had been found in the oriental literature. Although nocardiosis has been recognised throughout the rest of the world, most reports on it have originated from the United States and Europe. This case is the first report of endogenous Nocardia endophthalmitis in Japan and also the first case from outside of the United States. All reported cases of endogenous endophthalmitis were caused by Nocardia asteroides except for one case which was not determined in detail. ${ }^{7}$ Our case was also caused by $N$ asteroides. Beaman and associates ${ }^{2}$ reported that $N$ asteroides accounted for $86 \%$ of infections clinically limited to the lung, $92 \%$ of central nervous system infections, and $73 \%$ of systemic infections.

Delays in the early diagnosis and treatment of nocardiosis are often due to confusion with pulmonary tuberculosis, systemic mycoses, and the closely related actinomycosis. ${ }^{2}$ We initially confused the infection with one of fungal origin because of similarity of clinical features, the patient's past history, and cultivation of a
Candida sp. from the sputum. Candida sp, are sometimes cultured from the throat, intestinal duct, or sputum as clinically saprophytes. The correct diagnosis is imperative, because nocardiosis is refractory to antifungal agents. After pars plana vitrectomy $N$ asteroides was found to be the causative agent of the intraocular and pulmonary infections.

The distribution of nocardiosis by sex shows that men outnumber women by about $3: 1,{ }^{2}$ though for endogenous intraocular infections men outnumbered women by about 7:1. Most patients have been between the ages of 21 and 50, though the age range for Nocardia infections in the United States is broader. ${ }^{2}$ The 15 patients with endogenous Nocardia endophthalmitis were between the ages of 15 and 77 (average 46.2) years.

Presant and associates ${ }^{15}$ suggested that patients who had received corticosteroids or immunosuppressive therapy had a significantly higher mortality rate from localised nocardiosis than previously healthy persons or patients with serious underlying conditions but who were not receiving corticosteroids or immunosuppressive drugs. Ophthalmologists should consider endogenous Nocardia endophthalmitis as well as intraocular mycosis or tuberculosis when patients have metastatic infectious lesions in their ocular fundi while on corticosteroids or are on immunosuppressive therapy.

In this case the diagnosis was confirmed by examination of a specimen obtained from a pars plana vitrectomy. The diagnostic value of the vitrectomy was excellent, though the therapeutic effect was not clear. Sher et $a l^{10}$ reported a case of bilateral intraocular Nocardia infection, in which the condition in the left eye partially resolved after pars plana vitrectomy whereas the right eye, which had not undergone vitrectomy, had active ocular infection at the patient's death. In their case the diagnosis was established before the vitrectomy, and the patient was treated with several drugs for nocardiosis. They found filamentous beaded organisms resembling Nocardia in a specimen removed at surgery, though cultures of this material, inoculated on to several media, showed no growth after four weeks of incubation. We considered that Nocardia was not alive in their case at the time of the vitrectomy. On the other hand Nocardia was confirmed by both direct examination and cultures of the vitreous specimen in our case, and

TABLE II Summary of reported cases

\begin{tabular}{|c|c|c|c|c|c|}
\hline Study & Patient & Organism & Steroid & $\begin{array}{l}\text { Immunosuppressive } \\
\text { drug }\end{array}$ & Previous disease \\
\hline 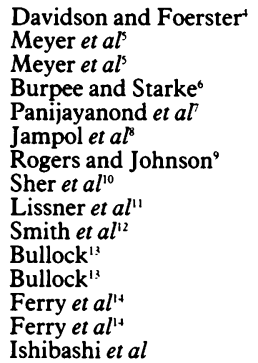 & $\begin{array}{l}46, M \\
67, M \\
56, M \\
20, M \\
50, M \\
40, M \\
77, \mathrm{~F} \\
38, M \\
60, M \\
23, M \\
15, M \\
59, M \\
66, M \\
49, \mathrm{~F} \\
27, M\end{array}$ & $\begin{array}{l}N \text { asteroides } \\
N \text { asteroides } \\
N \text { asteroides } \\
N \text { asteroides } \\
N \text { asteroides } \\
N \text { asteroides } \\
N \text { ocardia sp. } \\
N \text { asteroides } \\
N \text { asteroides } \\
N \text { asteroides } \\
N \text { asteroides } \\
N \text { asteroides } \\
N \text { asteroides } \\
N \text { asteroides } \\
N \text { asteroides }\end{array}$ & $\begin{array}{l}\text { Yes } \\
\text { No } \\
? \\
\text { No } \\
\text { Yes } \\
\text { Yes } \\
\text { Yes } \\
\text { Yes } \\
\text { Yes } \\
\text { Yes } \\
\text { Yes } \\
\text { No } \\
\text { No } \\
\text { Yes } \\
\text { Yes }\end{array}$ & $\begin{array}{l}\text { No } \\
\text { No } \\
? \\
\text { No } \\
\text { Yes } \\
\text { Yes } \\
\text { Yes } \\
\text { No } \\
\text { No } \\
\text { Yes } \\
\text { Yes } \\
\text { No } \\
\text { No } \\
\text { No } \\
\text { No }\end{array}$ & $\begin{array}{l}\text { Gall bladder disease } \\
\text { Gunshot wound } \\
\text { ? } \\
\text { Leg wound } \\
\text { Renal transplant } \\
\text { Wegener's granuloma, renal transplant } \\
\text { Malignant lymphoma } \\
\text { Hypogammaglobulinaemia } \\
\text { Hodgkin's disease } \\
\text { Lupus erythematosus, renal transplant } \\
\text { Paroxysmal nocturnal haemoglobinuria } \\
\text { Diabetes mellitus } \\
\text { ? } \\
\text { Scleroderma } \\
\text { Systemic lupus erythematosus }\end{array}$ \\
\hline
\end{tabular}

$\mathbf{M}=$ male. $\mathbf{F}=$ female 
adequate treatment was not performed at surgery, because the diagnosis was not definite. To determine the value of vitrectomy in the treatment of intraocular Nocardia infection we need more clinical experience and experimental study.

1 Dubos RJ, Hirsch JG. Bacterial and mycotic infections of man. 4th ed. Philadelphia: Lippincott, 1965.

2 Beaman BL, Burnside J, Edwards B, Causey W. Nocardia infections in the United States 1972-1974. F Infect Dis 1976; 134: $286-9$

3 Murray JF, Finegold SM, Froman S, Will DW. The changing spectrum of nocardiosis. A review and presentation of nine cases. Am Rev Respir Dis 1961; 83: 315-30.

4 Davidson S, Foerster HC. Intraocular nocardial abscess endogenous. Ophthalmology 1967; 71: 847-50.

5 Meyer SL, Font RL, Shaver RP. Intraocular nocardiosis. Report of three cases. Arch Ophthalmol 1970; 83: 536-41.

6 Burpee JC, Starke WR. Bilateral metastatic intraocular nocardiosis. Arch Ophthalmol 1971; 86: 666-9.
7 Panijayanond P, Oisson CA, Spivack ML, et al. Intraocular nocardiosis in a renal transplant patient. Arch Surg 1972; 194: 845-7.

8 Jumpol LM, Strauch BS, Albert DM. Intraocular nocardiosis Am $\mathcal{F}$ Ophthalmol 1973; 76: 568-73.

9 Rogers SJ, Johnson BL. Endogenous Nocardia endophthalmitis; Report of a case in a patient treated for lymphocytic lymphoma. Ann Ophthalmol 1977; 9: 1123-31.

10 Sher NA, Hill CW, Eifrig DE. Bilateral intraocular Nocardia asteroides infection. Arch Ophthalmol 1977; 95: 1415-8.

11 Lissner GS, O'Grady R, Choromokos E. Endogenous intraocular Nocardia asteroides in Hodgkin's disease. Am $\mathcal{F}$ Ophthalmol 1978; 86: 388-94.

12 Smith PW, Steinkraus GE, Henricks BW, Madson EC. CNS nocardiosis. Arch Surg 1980; 37: 729-30.

13 Bullock JD. Endogenous ocular nocardiosis: a clinical and experimental study. Trans Am Ophthalmol Soc 1983; 81: 451-531.

14 Ferry AP, Font RL, Weinberg RS, Boniuk M, Schffer CL. Nocardial endophthalmitis: report of two cases studied histopathologically. Brf Ophthalmol 1988; 72: 55-61.

15 Presant CA, Wiernik PH, Serpick AA. Factors affecting survival in nocardiosis. Am Rev Respir Dis 1973; 108: 1444 su
8. 